\title{
Composition, Structure and Tribotechnical Properties of TiN, MoN Single-Layer and TiN/MoN Multilayer Coatings
}

\author{
O. V. Bondar ${ }^{a}$, * B. A. Postol'nyi ${ }^{a}$, V. M. Beresnev ${ }^{b}$, G. Abadias ${ }^{c}$, P. Chartier ${ }^{c}$, O. V. Sobol ${ }^{d}$,
} D. A. Kolesnikov ${ }^{e}$, F. F. Komarov ${ }^{f}$, M. O. Lisovenko ${ }^{a}$, and A. A. Andreev ${ }^{g}$

${ }^{a}$ Sumy State University, vul. Rimskogo-Korsakova 2, Sumy, 40007 Ukraine

${ }^{b}$ Karazin Kharkiv National University, sq. Peremogy 4, Kharkiv, 61022 Ukraine

${ }^{c}$ University of Poitiers, Poitiers, Futuroscope, France

${ }^{d}$ National Technical University Kharkiv Polytechnic Institute, vul. Frunze 21, 61002 Kharkiv, Ukraine

${ }^{e}$ Belgorod State Research University, ul. Pobedy 85, Belgorod, 308015 Russia

${ }^{f}$ Belarussian State University, Minsk, 220030 Belarus

${ }^{g}$ NSC Kharkiv Institute of Physics and Technology, vul. Akademichna 1, Kharkiv, 61108, Ukraine

*e-mail: oleksandr.bondar@gmail.com

Received February 10, 2014

\begin{abstract}
Results of comprehensive investigations of nanostructed TiN and MoN single-layer coatings as well as multilayer coatings consisting of TiN/MoN alternating layers have been considered. The coatings have been deposited by a promising modern method of cathode-arc evaporation (vacuum-arc method). The elemental and phase compositions of coatings, their tribological and physico-mechanical properties: friction coefficient, wear, adhesion, hardness, and elastic modulus have been studied and the mechanisms of the coatings fracture have been discussed.
\end{abstract}

DOI: $10.3103 / \mathrm{S} 1063457615010050$

Keywords: vacuum-arc evaporation, Ti-Mo-N, phase and elemental composition, friction, hardness, wear, adhesion.

\section{INTRODUCTION}

At present the development of new protective coating to improve mechanical, physicochemical, and tribotechnical properties of metals and alloys [1-4] as well as products of them is the urgent direction of materials science, physics of solids, physics of plasma, chemistry, etc. [5-6].

Recently various methods of the surface modification have found a wide application: physicochemical (e.g., carbonitriding [7], nitriding [8]), ion-plasma (vacuum-arc evaporation [2], magnetron sputtering [3], and ion-plasma deposition [4-5]) as well as laser and electron beam machining, including pulse, machining by powerful ion beam and deposition of coatings by ablation $[1,6,8,9]$, treatment by a plasma jet with a flashing $[8,10]$, etc. All the above methods of the treatment and deposition of protective coatings have their advantages and disadvantages, as it follows from the analysis of publications [10-14]. One of the promising lines in producing protective coatings is the deposition from plasma obtained by vacuum-arc cathodic evaporation $[4,15-20]$.

In the present work we studied and compared characteristics of well known TiN coatings, less understood MoN coatings, and virtually uninvestigated multilayer (alternating) nanostructural TiN/MoN coatings having different (from 2 to $40 \mathrm{~nm}$ ) layer thicknesses.

It should be noted that recently multilayer, multicomponent, and nanostructured coatings are the basis for solving problems of the improvement of protective properties of surfaces of various products, in particular hardness, wear and corrosion resistances, oxidation resistance at high temperatures, stability to fatigue failure, etc. [21-25].

\section{METODS OF PRODUCING AND STUDYING COATINGS}

We studied samples of grade 3 steel and grade P6M5 high-speed steel of various sizes (e.g., steel discs up to $30 \mathrm{~mm}$ in diameter, up to $5 \mathrm{~mm}$ in thickness, in the as-supplied state). Before the deposition of coatings the 
samples surfaces were treated by glow discharge to clean from contaminations and activate. For the deposition of TiN, MoN, and multiperiod TiN/MoN coatings we used a Bulat-6 vacuum-arc plant with two evaporators (Ti and Mo) [4]. The plant is equipped with a source of dc voltage (from 5 to $1000 \mathrm{~V}$ ), generator of the pulse voltage with controlled amplitude of pulses from 0.5 to $2 \mathrm{kV}$ and repetition rate of 5-7 kHz. Thicknesses of TiN, MoN and TiN/MoN nanostructured coatings were varied from 4.9 to $8.2 \mathrm{~mm}$, the thicknesses of the TiN/MoN bilayers were chosen equal to 2, 10,20, and $40 \mathrm{~nm}$ with the total thickness of a coating from 6.8 to $8.2 \mu \mathrm{m}$.

Table 1 lists the conditions of the deposition of all types coatings (TiN, MoN and TiN/MoN multilayer) by the vacuum-arc method [1].

Table 1. Parameters of the coatings deposition

\begin{tabular}{c|l|c|c|c|c|c|c}
\hline Series & \multicolumn{1}{|c|}{ Material } & $I_{a}, \mathrm{~A}$ & $I_{f}, \mathrm{~A}$ & $U_{d c}, \mathrm{~V}$ & $U_{p}, \mathrm{~V}$ & $\begin{array}{c}\text { Frequency of pulses, } \\
\mathrm{kHz}\end{array}$ & $\begin{array}{c}p, \mathrm{~mm} \\
\text { mercurycolumn }\end{array}$ \\
\hline 1 & MoN & 170 & 0.6 & -40 & 1000 & 5 & $8 \times 10^{-4}$ \\
2 & MoN & 170 & 0.6 & -40 & 1000 & 5 & $5 \times 10^{-4}$ \\
3 & MoN & 100 & 1.0 & -40 & 1000 & 7 & $6 \times 10^{-4}$ \\
4 & TiN & 150 & 0.8 & -200 & 1000 & 5 & $4 \times 10^{-4}$ \\
5 & TiN/MoN, period 10 nm & $95-100$ & 0.8 & -40 & 1000 & 7 & $5 \times 10^{-4}$ \\
6 & TiN/MoN, period 20 nm & $95-100$ & 0.9 & -40 & 1000 & 7 & $5 \times 10^{-4}$ \\
7 & TiN/MoN, period 40 nm & $95-100$ & 1.0 & -40 & 1000 & 7 & $5 \times 10^{-4}$ \\
8 & TiN/MoN, period 10 nm & $95-100$ & 0.9 & -230 & - & - & $5 \times 10^{-4}$ \\
9 & TiN/MoN, period 10 nm & $95-100$ & 0.9 & -40 & 1000 & 7 & $5 \times 10^{-4}$ \\
10 & TiN/MoN, period10 nm & $95-100$ & 0.9 & -40 & - & - & $5 \times 10^{-4}$ \\
\hline
\end{tabular}

Note. $I_{a}$ is the arc current, $I_{f}$ is the focusing current.

To get complete information about the elemental composition of coatings, we used a device for the Reserford backscattering (RBS) of $\mathrm{He}^{+}$ions at energy of $1.7 \mathrm{MeV}$ (scattering angle $\theta=170^{\circ}$ if probing ions fall perpendicularly on samples, the detector energy resolution is $16 \mathrm{keV}$, the dose of helium ions is $5 \mu \mathrm{Cu}$ ) [26-29].

The microstructures and elemental compositions of coatings were studied using several electron-ion scanning microscopes (Quanta 200 3D, Quanta 600 FE-SEM) equipped with a detector of X-ray radiation of the PEGASUS 2000 system (EDAX, USA) [26-31]. We used also a JEOL-7001F scanning electron microscope (Japan) with a microanalysis by the energy dispersive X-ray spectroscopy (EDX). For the investigation of multilayer coatings and determination of their thickness, we prepared crosscut thin sections. The coatings structures and phase compositions were analyzed by X-ray diffraction analysis (XRD) in a $\mathrm{Cu} K_{\alpha}$ radiation (Bruker Advanced 8, DRON-3M) [31, 32]. The degree of the texture perfection, $\Delta \psi$, was defined from the width on a half-height of a diffraction line taken at the $\theta$-scanning [31-35]. A separation of diffraction profiles in the case of their overlapping was performed by the New_profile computer program of the separation overlapping lines, which was developed at the NTU Kharkiv Polytechnic Institute. The volume fractions of phases in a coating were calculated according to the standard procedure that allowed for the integral intensity and reflectivity of several lines of each phase. The phase composition was analyzed using the ASTM card file of the international standards.

Hardness and elastic modulus were measured using a device of the CSM Instruments company (Swiss). For tribological studies a Revetest scratch-tester (CSM Instruments) was used. We measured a friction coefficient, $\mu$, wear resistance, and acoustic emission by an indentation of a Rockwell-C pyramid into a sample.

\section{RESULTS AND DISCUSSION}

Figure 1a shows the EDX spectrum of a coating of the Mo-N system and Table 2 lists the corresponding elemental composition in weight and atomic percents. As it follows from these results, the $\mathrm{N}$ concentration is 14 at $\%$. Figure $1 \mathrm{~b}$ shows a section of the MoN coating, from which it is clearly seen that the resultant coating is of a high quality and has no discontinuity flaws. The coating thickness is $\sim 5 \mu \mathrm{m}$.

According to the EDX, the titanium mean content of coatings of the Ti-N system was 53 at $\%$ and nitrogen content was 47 at $\%$. The mean grain size of the TiN coating was $10-12 \mathrm{~nm}$. 


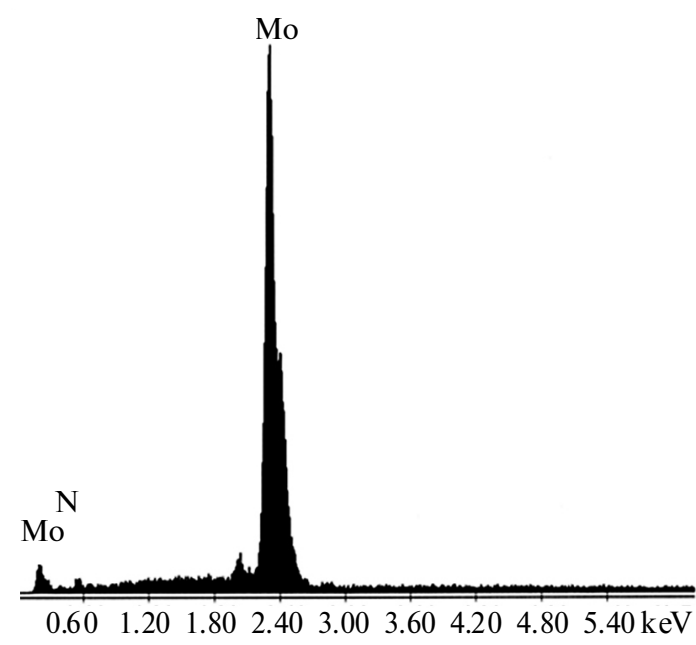

(a)

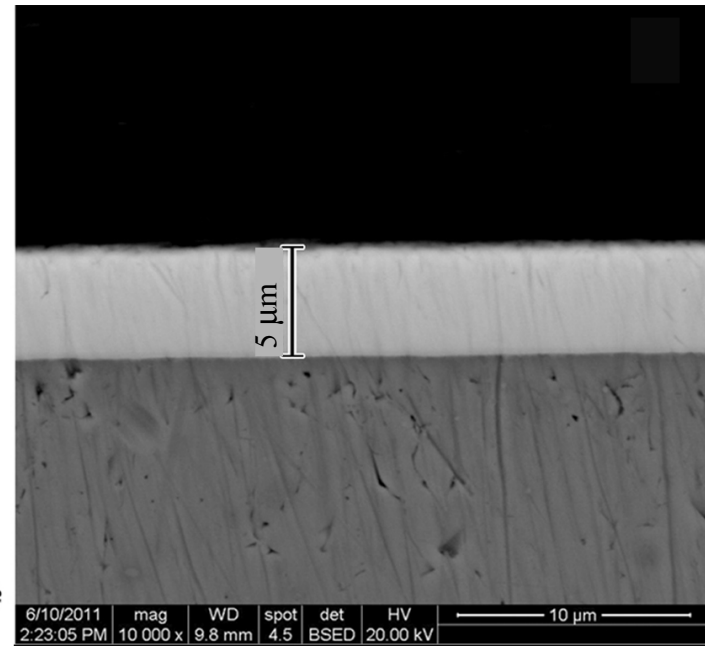

(b)

Fig. 1. Spectral analysis (EDX spectrum) (a) and a micrograph of the section (b) of the MoN coating.

Table 2. Elemental composition of a coating of series 1

\begin{tabular}{c|c|c}
\hline \multirow{2}{*}{ Element } & \multicolumn{2}{|c}{ Composition } \\
\cline { 2 - 3 } & wt \% & 13.53 \\
\hline $\mathrm{N}$ & 2.33 & 86.47 \\
$\mathrm{Mo}$ & 97.77 & 100.00 \\
Total & 100.00 & at $\%$ \\
\hline
\end{tabular}

For comparison the elemental analysis of multilayer coatings was made by two methods: RBS and SIMS (secondary ion mass-spectrometry). Figure 2 demonstrates micrographs of the cross section of a sample of series $5(\mathrm{TiN} / \mathrm{MoN})$ in an elemental contrast taken by EDX microanalysis using a JEOL-7001F (Japan).

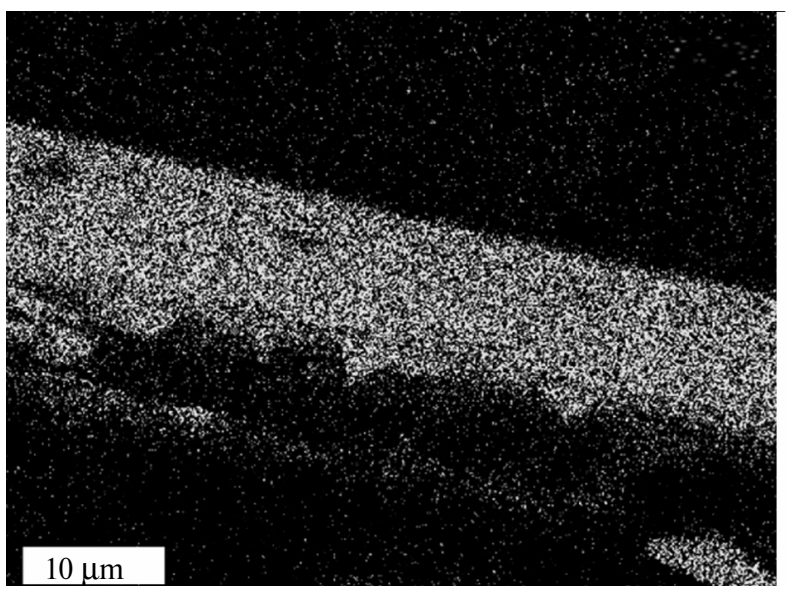

(a)

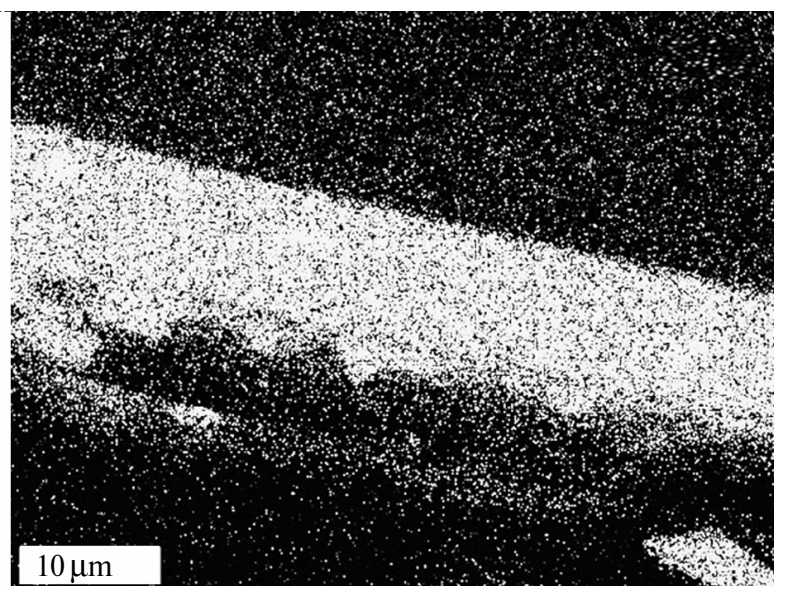

(b)

Fig. 2. Cross section of the MoN/TiN coating of series 5 in an elemental contrast ((a)-Mo, (b) - Ti).

Figure 3 shows the RBS energy spectrum with the energy $1.5 \mathrm{MeV}$ obtained for a sample with a TiN/MoN coating having the TiN monolayer $\sim 10 \mathrm{~nm}$ thick. The kinematic factors for Ti and Mo near the surface are indicated in the spectrum, the bends are also visible by which one can assess the thickness of each layer (first of all of the molybdenum nitride layer) by the concentration of Mo, as the $Z_{\mathrm{Mo}}$ is much higher than that of $\mathrm{Z}_{\mathrm{Fe}}$ (substrate) and $\mathrm{Z}_{\mathrm{Ti}}$. Thus, choosing a number of canals and knowing the loss of ions energy per a canal, one may determine the averaged thickness of a layer based on the section of an analyzing beam. In this case the thickness of a layer consisting of MoN is $10.8 \mathrm{~nm}$. Based on these curves the thickness of the first four layers 
from the coating surface may be defined. It should be noted that the thickness of the TiN layer is 19.2$19.4 \mathrm{~nm}$.

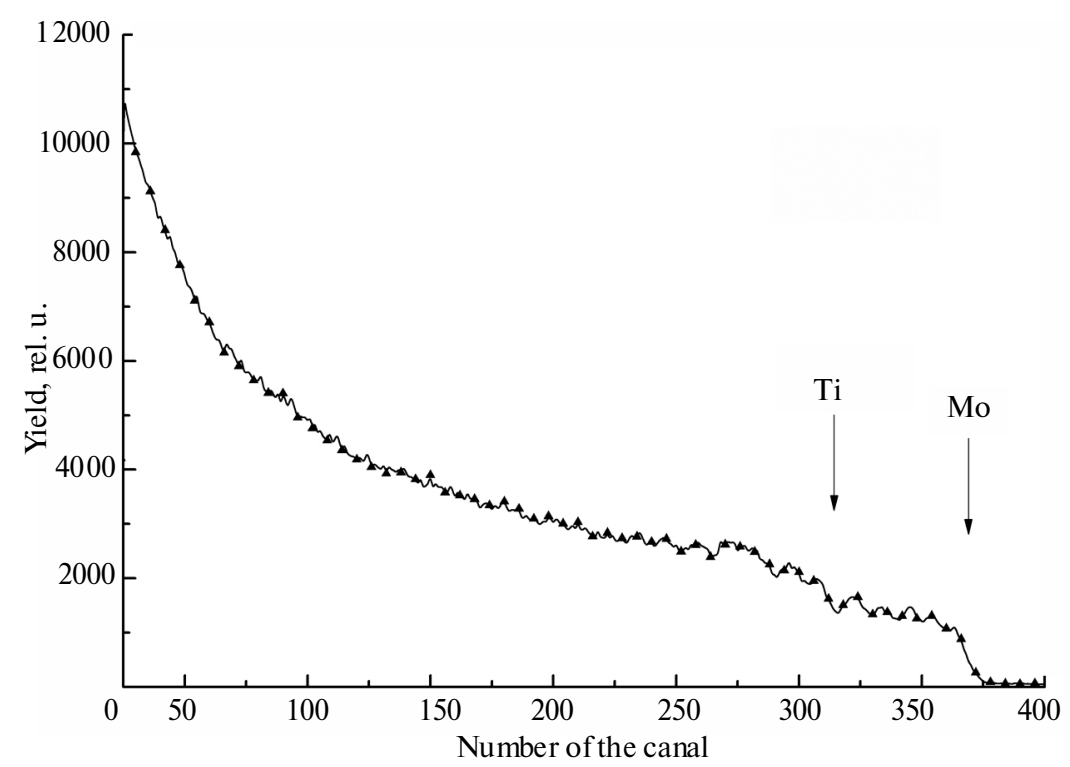

Fig. 3. Energy spectrum of the $4 \mathrm{He}^{+}$ions backscattering taken of a sample with the TiN/MoN coating of the 7 series.

The phase-structural analysis using the X-ray diffractometry showed that at the highest $(230 \mathrm{~V})$ dc negative bias voltage on a substrate the formation of crystallites with the preferred orientatation of the (111) plane parallel to the growth surface was typical (Fig. 4, spectrum 1).

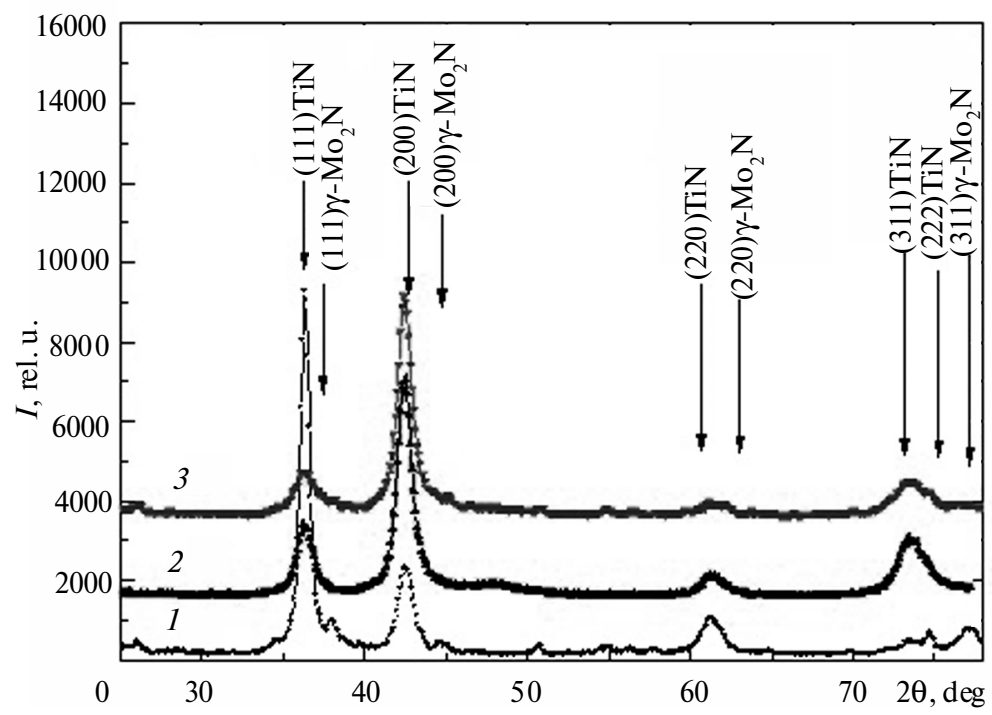

Fig. 4. Regions of diffraction spectra of TiN/MoN multilayer coatings obtained at the supply of a direct bias $-230 \mathrm{~V}$ (series 8 , spectrum 1), $-40 \mathrm{~V}$ (without an additional pulse action (series 10, spectrum 2) and with the additional action (series 9, spectrum 3).

The use of an additional high-frequency pulse action does not result in an essential change of a structure state of the material formed (Fig. 5). In this case as the layers thickness increases, the degree of the surface texturing, which is defined from the relative intensity of the (111) diffraction peak, increases. Thus, if we compare the relative intensities of peaks (111) and (200), we see that the intensity changes from 4.1 for layers of about $2 \mathrm{~nm}$ in thickness to 15.5 for layers $\sim 20 \mathrm{~nm}$ thick.

A decrease in the dc bias voltage that is supplied on the substrate in the course of the coating deposition to the $U_{d c}=-40 \mathrm{~V}$ gives rise to other type of the texture with the (200) plane parallel to the growth surface (see 
Fig. 4, spectra 2,3), which corresponds to the minimization of the free surface energy for the crystalline lattice of this type.

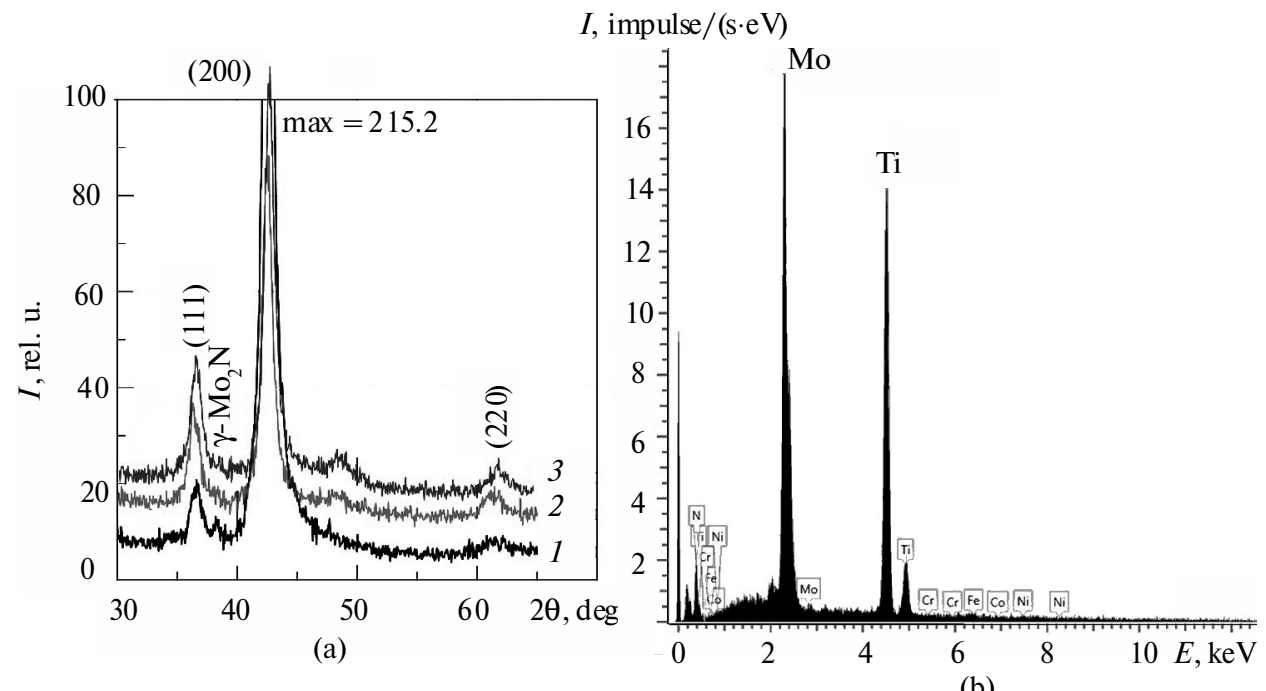

(b)

Fig. 5. Composition of TiN/MoN nanostructured multilayer coatings obtained using high-frequency pulse action: fragments diffraction spectra of coating samples with a period of 10 (1), 20 (2), and 40 (3) $\mathrm{nm}$ (a), energy dispersive spectrum of a sample with a multilayer nanocomposite coatings at the layer thickness $20 \mathrm{~nm}(\mathrm{~b})$.

From the comparison of diffraction spectra of coatings produced at $U_{d c}=-40 \mathrm{~V}$ with the additional pulse action of a kilovolt with a voltage, $U_{p}$ (see Fig. 4, spectrum 3) and without such an action (Fig. 4, spectrum 2) one can see that with a supply of high-voltage pulses the texturing degree of the multilayer system decreases.

Thus, for a multilayer system with the nanosized layer thickness, which is comparable with the depth of the implantable particle range at a high-energy pulse action, the additional pulse action inserts a disorienting influence on the crystallites formation in coating layers.

The analysis of the effect of the layer thickness on the structure and phase state of the coating shows that at the lowest TiN/MoN layers thickness $(10 \mathrm{~nm})$ and direct $(-230 \mathrm{~V})$ substrate voltage during the deposition a TiN and $\gamma-\mathrm{Mo}_{2} \mathrm{~N}$ two-phase coating with the ratio of phases about 90/10 forms. The main reason for the formation of two-phase state is the intensive ion bombardment, which promotes crushing of nanograins and onset of the formation of interphase boundaries. At the same time the formation of separate $\gamma-\mathrm{Mo}_{2} \mathrm{~N}$ layers with a cubic lattice occurs and thus, the interphase boundary forms.

As the period of TiN/MoN layers increases to $20 \mathrm{~nm}$ (Fig. 5a, spectrum 2), the formation of a two-phase structure with mean concentrations of TiN and $\gamma-\mathrm{Mo}_{2} \mathrm{~N}$ cubic phases of 60 and $40 \mathrm{vol} \%$ takes place. This correlates with the $\mathrm{Ti}$ : Mo concentrations ratio obtained with EDX, which are 62.3 and 36.8 at \%, respectively (see Fig. 5b). Figure 6a shows a section of a nanostructured coating. In Fig. $6 \mathrm{~b}$ the alternating nanosized layers are seen, dark regions correspond to TiN and bright to MoN.

An increase of the specific volume of interphase boundaries because of a high concentration of the second $\gamma-\mathrm{Mo}_{2} \mathrm{~N}$ phase is accompanied by a generation of high compression stresses in titanium nitride and achievement of the maximum hardness (27 GPa) (Fig. 7a).

It should be noted that only $\gamma-\mathrm{Mo}_{2} \mathrm{~N}$ phase forms in the molybdenum nitride layers and the $\beta-\mathrm{Mo}_{2} \mathrm{~N}$ phase is absent, though both these phases may form when coatings are produced by vacuum-arc and magnetron sputtering [19]. This may be explained by the two-stage formation of the phase composition of a multilayer nanostructured coating. At the initial moment of the $\mathrm{Mo}_{2} \mathrm{~N}$ phase growth the atomic sequence of the basal TiN lattice is a decisive factor, in further growth of the $\mathrm{Mo}_{2} \mathrm{~N}$ layer the cubic modification of $\gamma-\mathrm{Mo}_{2} \mathrm{~N}$ phase stabilizes, which due to the action of structural macrostresses in attaining relatively high thickness of the layer is accompanied by a drop of macrodeformation and a formation of an interphase boundary.

For samples with thickness of a coating layer $\sim 20 \mathrm{~nm}$ with thicker TiN and MoN layers the volume concentration of phases sufficiently accurately corresponds to the data expected according to the EDX, i.e., 70 of TiN and 30 of $\mathrm{Mo}_{2} \mathrm{~N}$ at $\%$. The increase of the layer thickness to $40 \mathrm{~nm}$ brings about the increase of the volume fraction of $\mathrm{Mo}_{2} \mathrm{~N}$ to $40 \%$, while hardness exhibits the lowest value and does not exceed $26 \mathrm{GPa}$. 


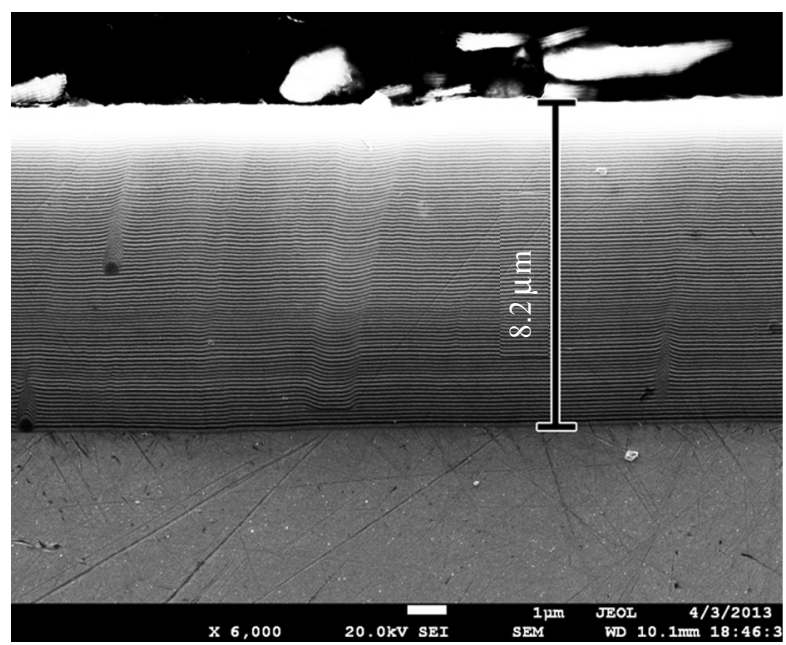

(a)

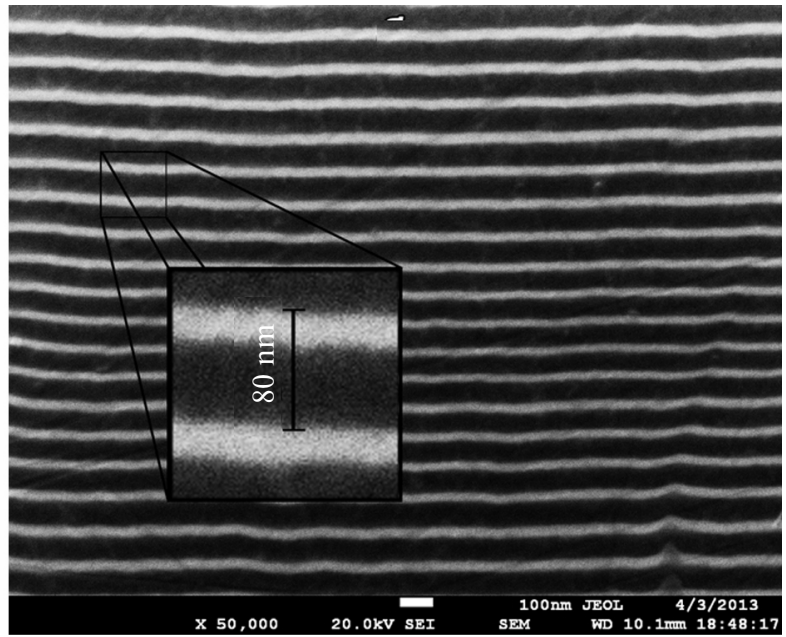

(b)

Fig. 6. Micrographs of the section of the TiN/MoN multilayer nanostructured coating $8.2 \mathrm{~mm}$ in thickness: general view, $6000 \times$ (a); a fragment of the section, thicknesss of a separate layer $20 \mathrm{~nm}, 50000 \times(\mathrm{b})$.

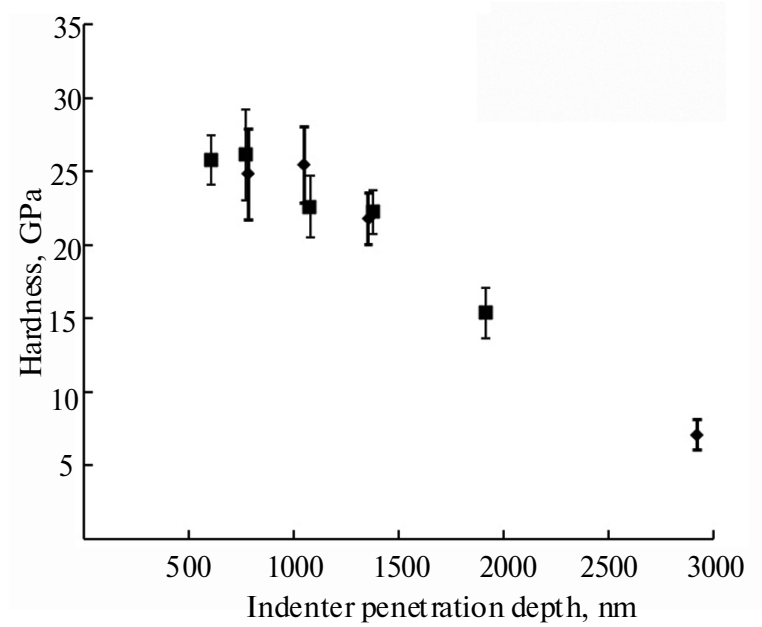

(a)

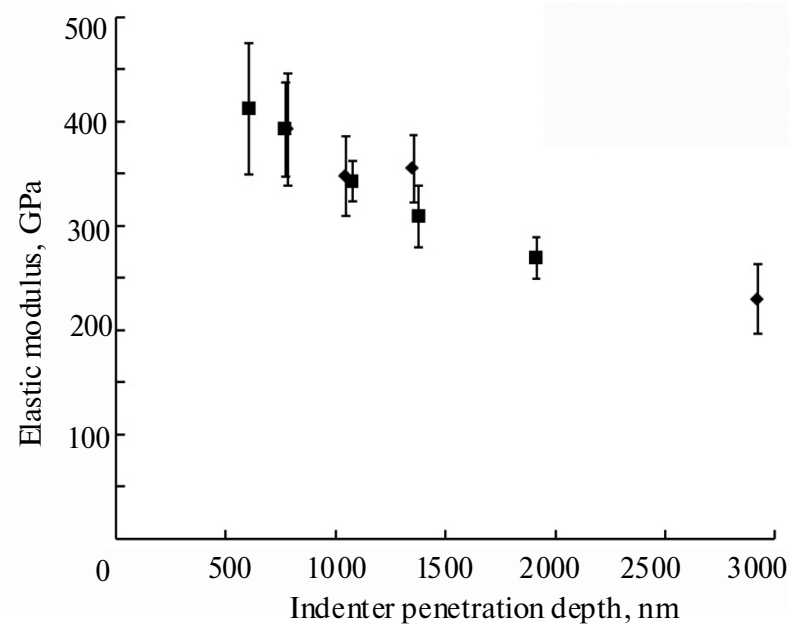

(b)

Fig. 7. Dependence of the microhardness (a) and elastic modulus (b) of TiN/MoN coatings with a periods of 20 ( $\square$ ) and $40(\checkmark) \mathrm{nm}$ on the indenter penetration depth.

The analysis of tribological properties of the obtained samples shows that the roughness $R a$ attains $0.3 \mu \mathrm{m}$, friction coefficient is in the range from 0.09 to 0.12 . The critical load, at which the coating starts to fracture, is $\sim 42.5 \mathrm{~N}$ at the layer thickness $\sim 40 \mathrm{~nm}$ and attains $60.1-64.8 \mathrm{~N}$ if the layers are 10 and $2 \mathrm{~nm}$ thick, i.e., the lower is the layer thickness, the higher is the load, which indicates that nanograins are covered by one layer of nitride. Therefore, the strength of a nanocomposite increases by keeping the grain boundaries from shifting (slipping). A possible mechanism of the increasing hardness of these heterostructures, according to the Koehler model [33,34], is the transfer of the valence charge, decrease of a nanograin size, and mixing entropy.

The hardness and elastic modulus values of the produced coatings are given in Table 3 and their dependences on the indenter penetration depth (or on the value of the indentation load) shown in Fig. 7. A typical dependence of $H$ and $E$ on the applied load is observed, i.e., the hardness and elastic modulus decrease with increasing depth of the indenter penetration and at high depths $(3000 \mathrm{~nm})$ at high loads the lowest hardness value $(7.5 \pm 1.0 \mathrm{GPa})$ and a decrease of the elastic modulus to $\sim 250 \mathrm{GPa}$ are observed.

Figure 8 presents friction trails for coatings under study at different stages of abrasion and Table 4 gives their tribotechnical characteristics, namely, values $L_{c 1}, L_{c 2}$, and $L_{c 3}$. It follows from these results that the highest adhesive characteristics had TiN coatings, for which the maximum $L_{c 1}, L_{c 2}$, and $L_{c 3}$ values were observed. The film fracture occurs at a load of about $90 \mathrm{~N}$, at the same time the friction coefficient values are noticeable 
higher, especially at the initial stages of wear $(0.13-0.14)$. For MoN coatings the minimum friction coefficient is in the range $0.02-0.07$ (depending on the deposition parameters).

Table 3. Hardness and elastic moduli of coating produced

\begin{tabular}{c|c|c|c|c|c|c}
\hline Characteristic & $\begin{array}{c}\text { TiN } \\
\text { (series 4) }\end{array}$ & $\begin{array}{c}\text { MoN } \\
\text { (series 3) }\end{array}$ & $\begin{array}{c}\text { MoN } \\
\text { (series 1) }\end{array}$ & $\begin{array}{c}\text { MoN } \\
\text { (series 2) }\end{array}$ & $\begin{array}{c}\text { MoN/TiN } \\
\text { (series 6) }\end{array}$ & $\begin{array}{c}\text { MoN/TiN } \\
\text { (series 5) }\end{array}$ \\
\hline$H, \mathrm{GPa}$ & 28 & 40 & 40.2 & 32 & $25-29$ & $26-31$ \\
$E, \mathrm{GPa}$ & 312 & $487-605$ & $512-520$ & $418-420$ & $392-400$ & $410-411$ \\
\hline
\end{tabular}

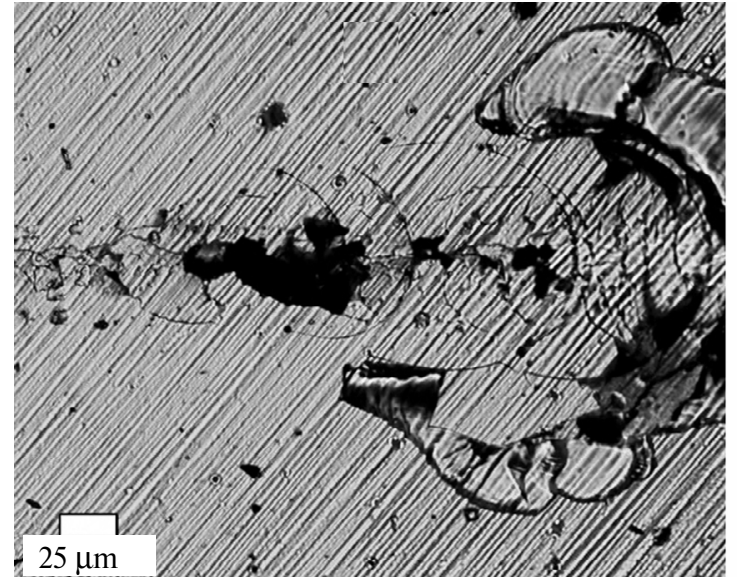

(a)

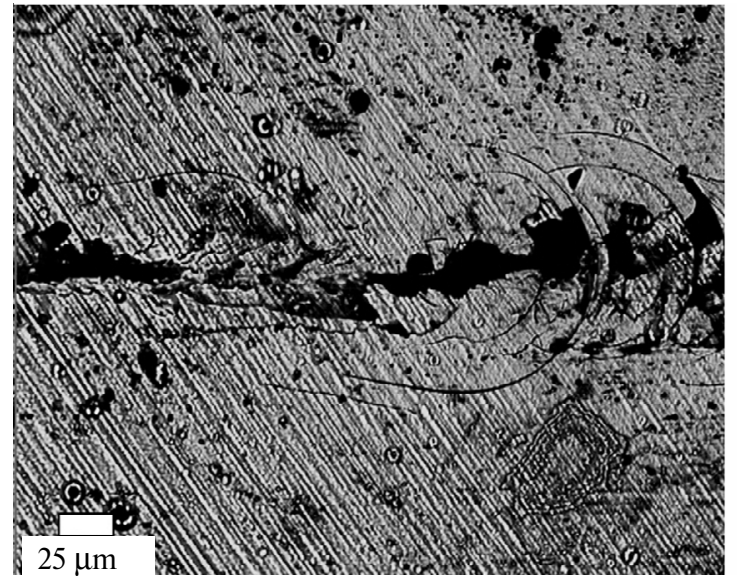

(c)

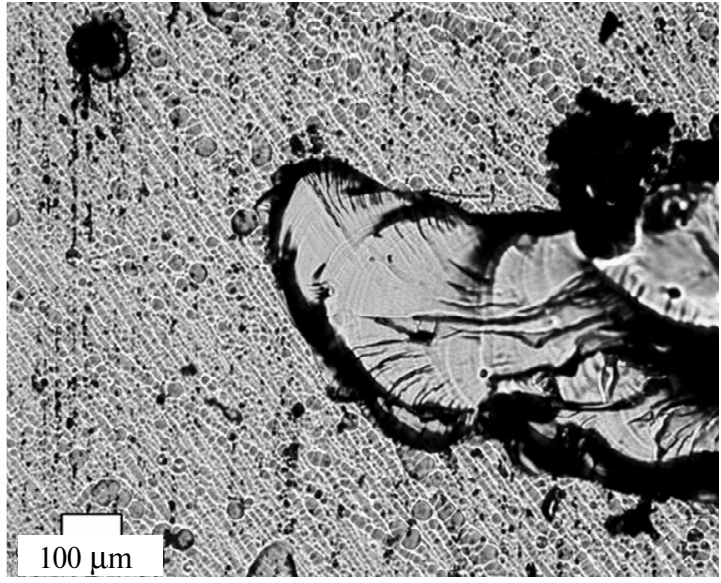

(b)

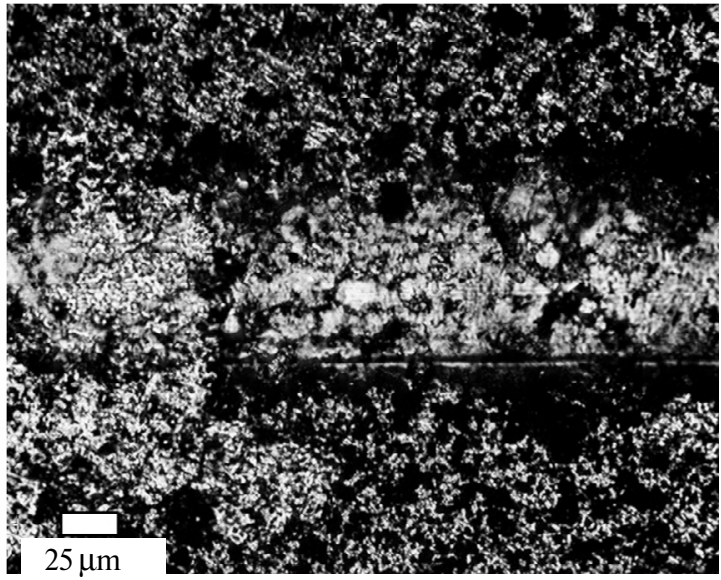

(d)

Fig. 8. Macrostructure of surfaces of nanocomposite materials (friction trails) for samples with: MoN, series 3 (à), 1 (b), 2 (c) and TiN, series $4(\mathrm{~d})$ coatings.

Figure 9 shows the results of the tests of the different types coatings of series 3 using a Revetest scratchtester and Table 4 gives characteristics of the tests for four series of coatings at the minimum averaged critical load $L_{c 1}=4.19 \mathrm{~N}$ and the load of the onset of the first crack appearance $L_{c 2}=7.6 \mathrm{~N}$.

It should be noted that as the load increases, the curve describing the dependence of a friction coefficient on the load has an oscillating mode, i.e., an increase of the friction coefficient is accompanied by a spurt of acoustic emission and a retardation of the indenter penetration into a material depth. The described behavior of all registered parameters indicates that a hard coating with a thickness of above $4 \mu \mathrm{m}$ on the surface of a softer material (steel) essentially affects the diamond indenter wear up to its complete abrasion at high loads. In testing coatings one can clearly distinguish various threshold values of the critical load, which lead to different types of fractures and only minimum (critical) load $L_{c 1}$ and the load of the onset of the appearance of the first crack may be related to adhesive fracture of coatings. 


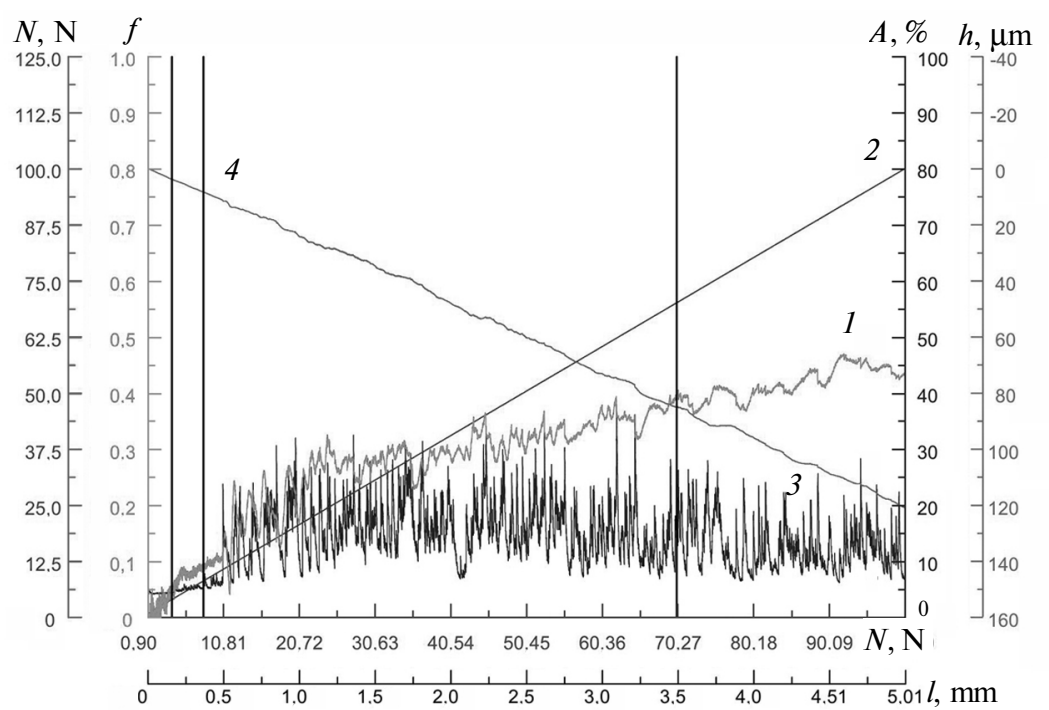

(a)
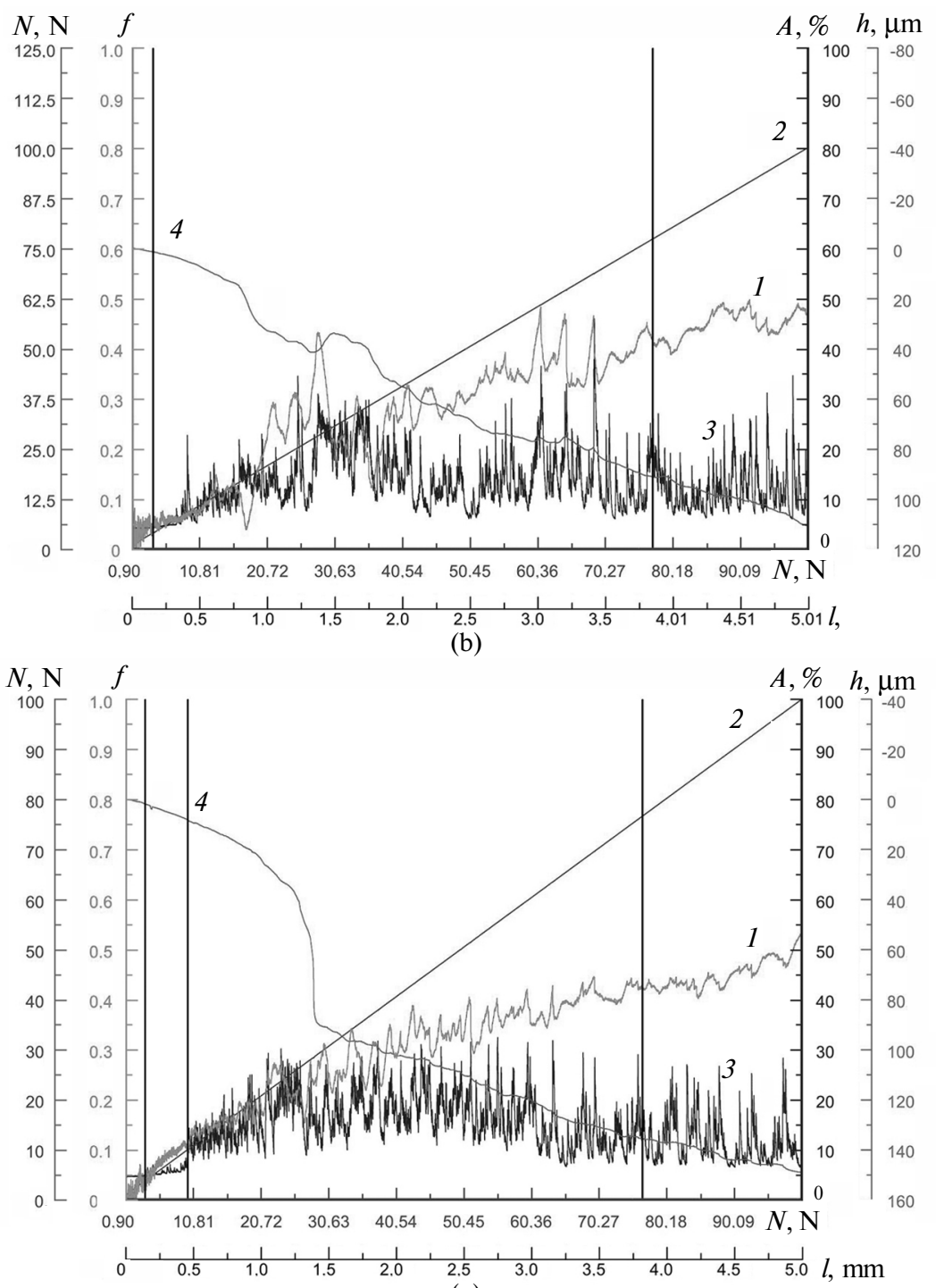

(c)

Fig. 9. Results of tribological tests of samples with MoN, series 3 (a), 1 (b), 2 (c), and TiN, series 4 (d) coatings: friction coefficient, $f_{c}(1)$, normal force, $N,(2)$; acoustic emission, A, (3), penetration depth, $h(4)$; along the X-direction-the normal force, $N$, and the groove length, $l$, at the loading. 


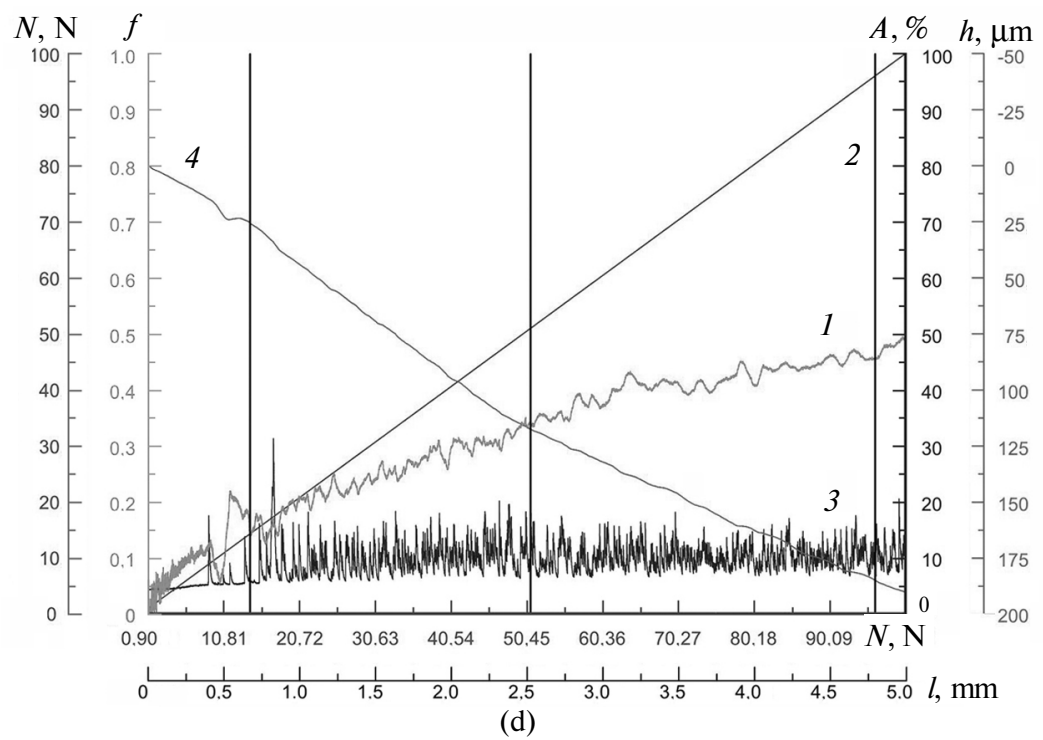

Fig. 9. (Contd.)

Table 4. Tribotechnical properties of samples under study

\begin{tabular}{c|c|c|c|c|c|c|c|c}
\hline \multirow{2}{*}{ Parameter } & \multicolumn{2}{|c|}{ Series 3 (MoN), scratch } & \multicolumn{2}{c|}{ Series 1 (MoN), scratch } & \multicolumn{2}{c|}{ Series 2 (MoN), scratch } & \multicolumn{2}{c}{ Series 4 (TiN), scratch } \\
\cline { 2 - 8 } & 1 & 2 & 1 & 2 & 1 & 2 & 1 & 2 \\
\hline$L_{c 1}$ & 4.36 & 4.02 & 0.91 & 3.52 & 3.65 & 4.44 & 14.17 & 11.66 \\
$L_{c 2}$ & 7.15 & 8.15 & 3.90 & 18.29 & 9.91 & 11.79 & 50.96 & 39.38 \\
$L_{c 3}$ & 67.24 & 70,06 & 77.28 & 72.9 & 76.72 & 77.64 & 96.1 & 80.87 \\
$f_{c}$ & $0.07-0.40$ & $0.06-0.40$ & $0.07-0.48$ & $0.05-0.51$ & $0.06-0.045$ & $0.09-0.43$ & $0.15-0.46$ & $0.12-0.43$ \\
\hline
\end{tabular}

The coating fracture starts with the appearance of separate chevron cracks at the bottom of a wear groove (see Fig. 9), which causes the increase of local stresses and friction force and results in a fast subsequent abrasion of coatings. This fact is also confirmed in $[33,35]$ in the study of the abrasion of hard and superhard $(\geq 40 \mathrm{GPa}$ ) nanostructured coatings.

Judging by the results of adhesive tests, the cohesive fracture of a coating of series 3 comes at the minimum (critical) load, $L_{c 1}=4.19 \mathrm{~N}$ and adhesive fracture (plastic abrasion) comes at a load of $L_{c 2}=7.65 \mathrm{~N}$, which corresponds to the onset of the first crack appearance. The critical load of the cohesion-adhesion fracture $L_{c 3}$ attains 81-97 N.

The friction coefficient, $f_{c}$, of series $1-3$ samples with MoN coatings at the initial stage is $0.05-0.07$ and after the first crack appearance (at adhesive fracture) increases by a factor of a minimum 2.0-2.5. For a TiN coating the friction coefficient at the initial stage of abrasion is $0.12-0.15$ and with appearance of the first crack (at adhesive fracture) increases by tens percents, which essentially differs from samples with MoN coatings (Fig. 10).

For a MoN/TiN multilayer system it was established that the minimum value $(42.5 \mathrm{~N})$ of the critical load of the fracture corresponds to a periodic structure with the highest $(40 \mathrm{~nm})$ period. For a structure with a period of $20 \mathrm{~nm}$ this value increases to $61.0 \mathrm{~N}$ and with a period of $\sim 10 \mathrm{~nm}$ it is $64.8 \mathrm{~N}$. Thus, in a multilayer system the use of very thin layers, which lead to an increase of the specific density of interphase boundaries per unit layer thickness, increases the critical load of fracture.

\section{CONCLUSIONS}

By the complex analysis of tribological and physico-mechanical properties (friction coefficient, wear, adhesion, hardness, elastic modulus) of TiN and MoN nanostructured coatings as well as multilayer coatings consisting of TiN/MoN alternating layers it has been shown that these coatings are promising for using as protective coatings for cutting tools, turbine blades, walls of chemical and nuclear reactors. 


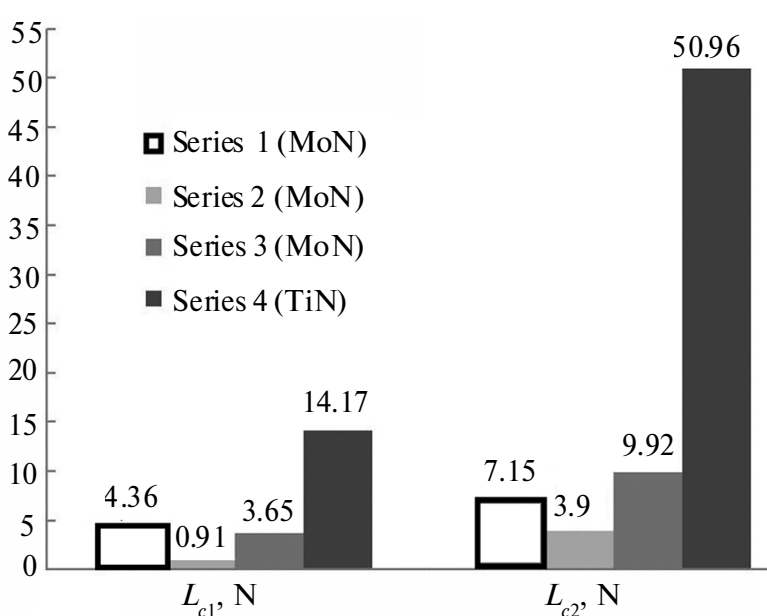

(a)

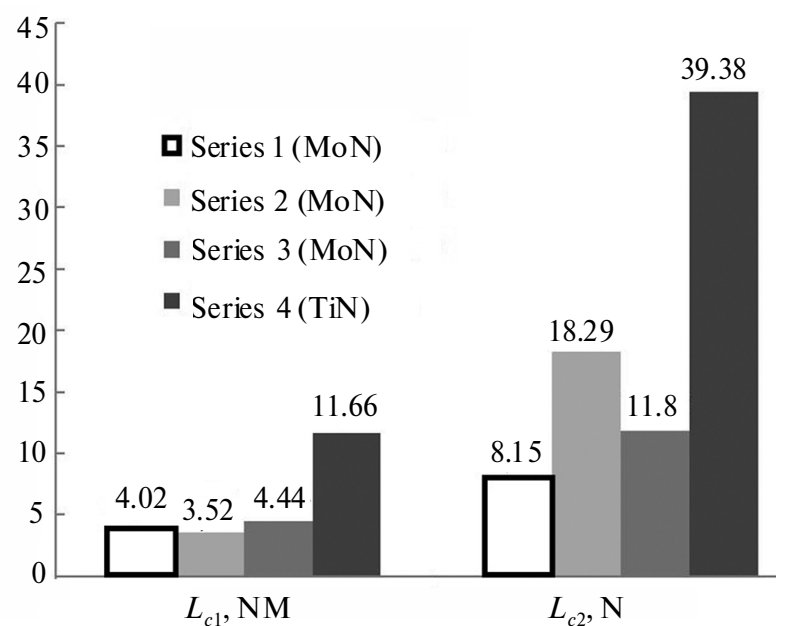

(b)

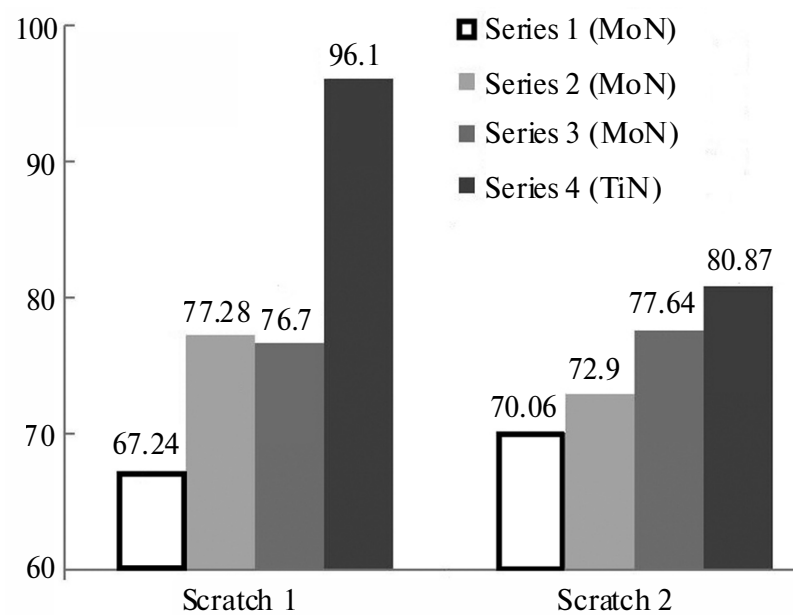

(c)

Fig. 10. Tribotechnical properties of the studied samples with MoN coatings (series 1-3) and TiN coating (series 4) at minimum critical loads $L_{c 1}, L_{c 2}$ (scratches 1 (a) and $\left.2(\mathrm{~b})\right)$ and $L_{c 3}$ (scratches 1 and 2 (c)).

Over the whole range of thicknesses, including nanosized, of a multiperiod coating the formation of TiN and $\gamma-\mathrm{Mo}_{2} \mathrm{~N}$ phases with the fcc crystal lattice takes place. In periodic TiN/MoN structures a change in a layer thickness has been found to result in a change of the percentage ratio of the TiN and $\gamma-\mathrm{Mo}_{2} \mathrm{~N}$ phases as well as of the hardness and elastic modulus values. For a multilayer system with layers of a nanosized thickness, which is comparable with a depth of implantable particles range at a high-energy plasma action, an additional pulse action has been shown to result in a disordering effect on the formation of crystallites in coating layers.

The friction coefficient, $f_{c}$, of the MoN coatings that has been measured by scratch tests is lower than of TiN coatings, especially at the initial stages of abrasion. In the course of adhesive tests two mechanisms of coatings fracture have been revealed: the cohesive one at the minimum critical load, $L_{c 1}$, and adhesive mechanism of fracture (plastic abrasion) at the appearance of the first crack at load $L_{c 2}$.

In the MoN/TiN multilayer system the use of very thin layers, which lead to an increase of the specific density of interphase boundaries per layer thickness unit, has been shown to increase the critical load of fracture.

The work was done in the framework of the scientific and technical program of the cooperation with the University of Poitiers (France) as well as of the Development of the Fundamentals of the Formation of Superhard Nanostructured Multicomponent Coatings with High Physical and Mechanical Characteristics (No. 0112U001382) and Physical Principles of Plasma Technology for the Complex Machining of Multicomponent Materials and Coatings No. 0113U000137c) UA complex state budget programs.

The authors thank Prof. Pogrebnjak for his help in the performance of the experiments and interpretation of the results obtained. 


\section{REFERENCES}

1. Pogrebnjak, A.D. and Tyurin, Y.N., Modification of material properties and coating deposition using plasma jets, Physics-Uspekhi, 2005, vol. 48, no. 5, pp. 487-514.

2. Pogrebnjak, A.D., Shpak, A.P., Azarenkov, N.A., and Beresnev, V.M., Structures and properties of hard and superhard nanocomposite coatings, Ibid., 2009, vol. 52, no. 1, pp. 29-54.

3. Nanostrukturnye pokrytiya (Nanostructured coatings), Cavaleiro, A. and De Hosson, J. Th. M., Eds., Moscow: Tekhnosphere, 2011.

4. Azarenkov, N.A., Sobol', O. V., Pogrebnjak, A.D., and Beresnev, V. M., Inzheneriya vakuumno-plasmennukh pokrutii (Engineering of vacuum-plasma coatings), Kharkov: Karazin Kharkov National University, 2011.

5. Pogrebnjak, A.D., Sobol, O.V., Beresnev, V.M., Turbin, P.V., Kirik, G.V., Makhmudov, N.A., Il'yashenko, M.V., Shypylenko, A.P., Kaverin, M.V., Tashmetov, M.Yu. and Pshyk, A.V., Phase composition, thermal stability, physical and mechanical properties of superhard on base $\mathrm{Zr}-\mathrm{Ti}-\mathrm{Si}-\mathrm{N}$ nanocomposite coatings, in Nanostructured Materials and Nanotechnology IV: Ceramic Engineering and Science Proceedings, 2010, vol. 31, no. 7, pp. 127-138.

6. Pogrebnjak, A.D. and Tolopa, A.M., A review of high-dose implantation and production of ion mixed structures, Nucl. Instrum. Meth., 1990, vol. 52, pp. 25-43.

7. Boyko, V.I., Valyaev, A.N., and Pogrebnyak, A.D., Metal modification by high-power pulsed particle beams, PhysicsUspekhi, 1999, vol. 169, no. 11, pp. 1243-1271.

8. Tyurin, Yu.N. and Zhadkevich, M.L., Plazmennye uprochnyayushchie tekhnologii (Plasma strengthening technologies), Kiev: Naukova Dumka, 2008.

9. Podgornik, B. and Vizintin, J., Wear resistance of pulse plasma nitrided AISI 4140 and A355 steels, Mater. Sci. Eng. $A, 2001$, vol. 315 , no. $1-2$, pp. $28-34$.

10. Grimanelis, D. and Eyre, T.S., Wear characteristics of a diffusion bonded sintered steel with short term surface treatments, Wear, 2007, vol. 262, no. 1-2, pp. 93-103.

11. Pantelis, D.I., Bouyiouri, E., Kouloumbi, N., Vassiliou, P., and Koutsomichalis, A., Wear and corrosion resistance of laser surface hardened structural steel, Surf. Coat. Technol., 2002, vol. 161, no. 2-3, pp. 125-134.

12. Todaka, Y., Umemoto, M., Li, J., and Tsuchiya, K., Nanocrystallization of carbon steels by shot peening and drilling, Rev. Adv. Mater. Sci., 2005, vol. 10, pp. 409-416.

13. Lavrentiev, V.I. and Pogrebnjak, A.D., High-dose ion implantation into metals, Surf. Coat. Technol., 1998, vol. 99, no. 1 , pp.24-32.

14. Ivasishin, O.M., Pogrebnjak, A.D., and Bratushka S.N., Nanostructured layers and coating formed by ion-plasma fluxes in titanium alloys and steels, Kiev: Akademperiodyka, 2011.

15. Pogrebnyak, A.D., Beresnev, V.M., Kaverina, A.Sh., Kolesnikov, D.A., Yakushchenko, I.V., Ilyashenko, M.V., and Makhmudov, N.A., Adhesive strength and physical, mechanical, and triboengineering properties of nano- and microstructural $\mathrm{Al}_{2} \mathrm{O}_{3}$ coatings, J. Friction Wear, 2012, vol. 33, no. 3, pp. 195-202.

16. Pogrebnjak, A.D., Bratushka, S., Boyko, V.I., Shamanin, I.V., and Tsvintarnaya, Yu.V., A review of mixing processes in $\mathrm{Ta} / \mathrm{Fe}$ and $\mathrm{Mo} / \mathrm{Fe}$ systems treated by high current electron beams, Nuclear Instruments and Methods in Physics Research Section B: Beam Interactions with Materials and Atoms, 1998, vol. 145, no. 3, pp. 373-390.

17. Kadyrzhanov, K.K, Komarov, F.F., Pogrebnjak, A.D., et al., Ionno-luchevaya i ionno-plazmennaya modifikatsiya materialov (Ion-beam and ion-plasma modification of materials), Moscow: Mosk. Gos. Univ., 2005.

18. Pogrebnjak, A.D., Bondar, O.V., Sobol, O.V. and Beresnev, V.M., Changing of defect's structure and properties of superhard nanostructured Ti-Si-N coatings, fabricated using CPVD, before and after annealing, Soft Nanosci. Lett., 2013, no. 3, pp. 46-51

19. Pogrebnjak, A.D., Eyidi, D., Abadias, G., Bondar, O.V., Beresnev, V.M., and Sobol, O.V., Structure and properties of arc evaporated nanoscale TiN/MoN multilayered systems, Int. J. Refract Met. Hard Mater., 2015, vol. 48, pp. 222-228.

20. Azarenkov, N.A., Sobol, O.V., Beresnev, V.M., Pogrebnyak, A.D., Kolesnikov, D.A., Turbin, P.V., and Toryanik, I.N., Vacuum-plasma coatings based on the multielement nitrides, Metallofizika i Noveishie Tekhnologii, 2013, vol. 35, no. 8, pp. 1061-1084.

21. Uglov, V.V., Cherenda, N. N., Anishchik, V. M., et al., Structure and composition of coatings, formed in the course of machining materials by compressive and plasma fluxes, Physics Chemistry of Machining Materials, 2005, vol. 4, pp. 28-32.

22. Pogrebnyak, A.D., Beresnev, V.M., Kaverina, A.Sh., et al., Formation of superhard Ti-Hf-Si-N/NbN/ $\mathrm{Al}_{2} \mathrm{O}_{3}$ multilayer coatings for highly effective protection of steel, Tech. Phys. Let., 2013, vol. 39, no. 2, pp. 189-192.

23. Pogrebnjak, A.D., Structure and properties of nanostructured (Ti-Hf-Zr-V-Nb) N coatings, J. Nanomater., 2013, art. ID 780125.

24. Pogrebnjak, A.D., Bratushka, S.N., Beresnev, V.M., and Levintant-Zayonts, N., Shape memory effect and superelasticity of titanium nickelide alloys implanted with high ion doses, Russian Chem. Rev., 2013, vol. 82, no. 12, pp. 11351159.

25. Pogrebnjak, A.D., Shpak, A.P., Beresnev, V.M., et al., Effect of thermal annealing in vacuum and in air on nanograin sizes in hard and superhard coatings Zr-Ti-Si-N, J. Nanosci. Nanotech., 2012, vol. 12, pp. 9213-9219. 
26. Koltunowicz, T.N., Zhukowski, P., Fedotov, A.K., et al., Influence of matrix type on negative capacitance effect in nanogranular composite films FeCoZr-insulator, Elektronika i Elektrotechnika, 2013, vol. 19, no. 4, pp. 37-40.

27. Lyashenko, I.A., Khomenko, A.V., and Metlov, L.S., Phenomenological theory for the melting of a thin lubricant film between two atomically smooth solid surfaces, Tech. Phys., 2010, vol. 55, no. 8, pp. 1193-1199.

28. Komarov, A.F., Komarov, F.F., Mironov, A.M., et al., Formation of $\mathrm{C}_{x} \mathrm{~N}_{y}$ films by high dose nitrogen implantation in the layered structures, Vacuum, 2003, vol. 70, no. 2-3, pp. 141-145.

29. Zhukowski, P., Koltunowicz, T.N., Fedotova, J.A., and Larkin, A.V., An effect of annealing on electric properties of nanocomposites $(\mathrm{CoFeZr})_{x}\left(\mathrm{Al}_{2} \mathrm{O}_{3}\right)_{1-x}$ produced by magnetron sputtering in the atmosphere of argon and oxygen beyond the percolation threshold, Przeglad Elektrotechniczny, 2010, vol. 86, no. 7, pp. 157-159.

30. Khomenko, A.V. and Prodanov, N.V., Molecular dynamics simulations of ultrathin water film confined between flat diamond plates, Condensed Matter Physics, 2008, vol. 11, no. 4 (56), pp. 615-626.

31. Pogrebnjak, A.D., Ponomarev, A.G., Shpak, A.P., and Kunitskii, Yu.A., Application of micro- and nanoprobes to the analysis of small-sized 3D materials, nanosystems, and nanoobjects, Physics-Uspekhi, 2012, vol. 55, no. 3, pp. 270300.

32. Tyurin, Y.N. and Pogrebnjak, A.D., Electric heating using a liquid electrode, Surf. Coat. Technol., 2001, vol. 142144 , pp. 293-299.

33. Veprek, S. and Veprek-Heijman, M.G.J., Limits to the preparation of superhard nanocomposites: impurities, deposition and annealing temperature, Thin Solid Films, 2012, vol. 522, pp. 274-282.

34. Koehler, J.S., Attempt to design a strong solid, Phys. Rev. B, 1970, vol. 2, no. 2, pp. 547-551.

35. Musil, J., Hard nanocomposite coatings: Thermal stability, oxidation resistance and toughness, Surf. Coat. Technol., 2012, vol. 207, pp. 50-65.

Translated by G. Kostenchuk 